\title{
Antimicrobial properties of diethylamine NONOate, a nitric oxide donor, against Escherichia coli: a pilot study
}

\author{
Annette M. Sysel ${ }^{1,2} \cdot$ Michael J. Dunphy ${ }^{2,3} \cdot$ Joseph A. Bauer $\mathbb{1}^{1,2}$
}

Received: 29 September 2020 / Revised: 18 November 2020 / Accepted: 19 November 2020 / Published online: 28 December 2020

(c) The Author(s), under exclusive licence to the Japan Antibiotics Research Association 2020

\begin{abstract}
The emergence of SARS-CoV-2, the causative agent of COVID-19, highlights the increasing need for new and effective antiviral and antimicrobial agents. The FDA has recently banned several active ingredients used in hand sanitizers, including triclosan and benzethonium chloride. Nitric oxide (NO) is involved in the innate immune response and is a major component of macrophage-mediated attack on foreign viruses and bacteria. The specific aim of this study was to assess the antibacterial effects of 2-(N,N-diethylamino)-diazenolate-2-oxide (DEA-NONOate) against Escherichia coli (E. coli). A bacterial growth assay was compared to an adenosine triphosphate (ATP) activity assay at various time points to assess effects of DEANONOate on $E$. coli growth. A UV/Vis spectrophotometer was used to determine concentration of $E$. coli by measuring optical density (OD) at $630 \mathrm{~nm}$. A luminescent assay was used to measure ATP activity correlating to viable cells. DEANONOate at a concentration of $65 \mathrm{mM}$ was able to inhibit the growth of $E$. coli with the same efficacy as $1 \mu \mathrm{g} \mathrm{ml} l^{-1}$ concentration of ciprofloxacin. Both the OD and ATP assays demonstrated a $99.9 \%$ reduction in E. coli. Both a $1 \mu \mathrm{g} \mathrm{ml} l^{-1}$ concentration of ciprofloxacin and a $65 \mathrm{mM}$ concentration of DEA-NONOate achieved $99.9 \%$ inhibition of $E$. coli, verified using both optical density measurement of bacterial cultures in 96 well plates and a luminescent ATP activity assay. The bactericidal effects of DEA-NONOate against $E$. coli is proof-of-concept to pursue evaluation of nitric oxide-based formulations as antimicrobial and antiviral agents as hand sanitizers.
\end{abstract}

\section{Introduction}

One of the challenges of evaluating antimicrobial agents as hand sanitizers is the United States Food and Drug Administration (FDA) gold standard use of the viable plate count method, which utilizes bacteria diluted on agar plates to quantify colony forming units (CFU) following 20-24h of incubation [1]. Interestingly, the counting of CFUs to assess antimicrobial efficacy has remained relatively unchanged since the seminal work of microbiology [2], which established the validation criteria for $\mathrm{CFU}$ counting. Based on counting of more than 1000 agar plates, Breed and Dotterrer determined that the number of CFUs at the end of an experiment should be between 40 and 200 colonies per plate to validate

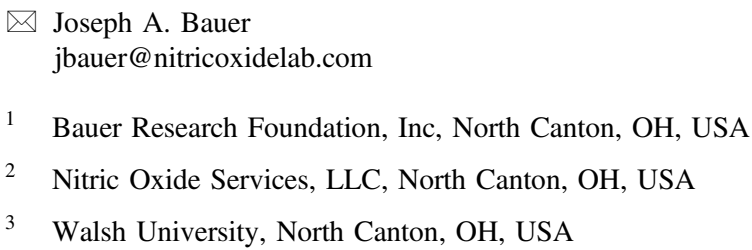

antimicrobial activity. Other microbiologists have recommended ranges between 25 and 250 CFUs [3]. Thus, dilutions of $1: 100,000\left(10^{-5}\right), 1: 1,000,000\left(10^{-6}\right)$ or even $1: 10,000,000$ $\left(10^{-7}\right)$ of bacteria are generally required to achieve a valid number of CFUs for testing antibiotic efficacy. Such dilutions are, however, tedious to perform and prone to errors.

Both the FDA and the field of microbiology are interested in developing new assays to aid in the development of hand sanitizers by replacing outdated serial dilutions and agar plate incubations that rely on manual or computer-aided colony counts. Several high-throughput assays, including broth dilution microplate assays, quantitative polymerase chain reaction assays, enzymatic assays and luminescent assays have been used to complement the viable plate count method for evaluation of antimicrobial activity [4-10]. The BacTiter$\mathrm{Glo}^{\mathrm{TM}}$ assay is a luminescent assay that determines the number of viable bacterial cells by quantitation of adenosine triphosphate (ATP), which is a vital measure of mitochondrial cellular respiration required for cell survival. ATP bioluminescent assays have been used to effectively evaluate antibacterial properties of various antimicrobial test agents [1114]. The efficacy of antibacterial agents is associated with a 
decrease in cellular respiration, which correlates to a decrease in ATP activity [15].

Nitric oxide (NO), is a free radical and ubiquitous signaling molecule which inhibits cellular respiration [16]. NO was discovered alongside oxygen by chemist Joseph Priestly [17]. Several studies have shown that NO and its surrogates are involved in a variety of physiologic as well as pathologic processes including cardiovascular disease [18], vascular dysfunction [19], asthma [20], pulmonary disorders [21], sepsis [22], retinopathy [23], and cancer [24, 25]. NOgenerating drugs such as glyceryl trinitrate (nitroglycerin) [26] and sodium nitroprusside [27] were first used clinically for treatment of angina and regulation of hypertension respectively. More recently, NO has been used to treat Sudden Acute Respiratory Syndrome [28], Pediatric Acute Respiratory Distress Syndrome [29] and COVID-19 [30, 31], shedding light on the clinical importance of harnessing NO in a biologically compatible and useful form as a therapeutic intervention.

Nitric oxide (NO) is one of the most functionally diverse, ubiquitous, and biologically dichotomous molecules in nature, contributing to physiology as well as pathology in almost every biological setting. The doubleedged nature of $\mathrm{NO}$ is a function of three principle factors: (1) site of NO production/delivery, (2) NO concentration, and (3) duration of NO production/delivery. NO is generated enzymatically in vivo by three enzymes known as NO synthases: NOS-1, NOS-2, and NOS-3 [32]. In addition, NO can be produced by a NO-recycle pathway from nitrate and nitrite precursors [33-35], elevating these once-considered inert end products to biological surrogates of NO. Nitric oxide is a crucial component of both innate and adaptive defense mechanisms and is involved in $\mathrm{T}$ cell-mediated immunity as well as in macrophagemediated killing of intracellular bacteria [36-38]. As a free radical, NO can react with other molecules to produce reactive oxygen species (ex. Superoxide) and reactive nitrogen species (ex. peroxynitrite), which together contribute to the regulation of the immune response [39].

NO exists as a gas, and as such has proved challenging to manage for biomedical applications. Discovery of the widespread biological activities of NO have ultimately led to the development of solid, convenient dosage forms to harness NO gas, namely "NO-donors." The first class of NO donors, which were tested for biological activity were NONOates or diazeniumdiolates [40, 41]. NONOates can be distinguished from each other based on the half-life of NO release (seconds to hours) as well as the number of moles of NO released. Thus, the physiologic or pathologic effects of NO from a NONOate can be controlled by selecting a specific NO-donor to promote cell death or invoke cellular responses. NO donors have demonstrated antibacterial, antiviral, and antitumor properties and have been included in biofilms, nanoparticles and hydrogels to expand delivery options [42-48]. Current trends in overcoming antibiotic resistance have utilized NO donors as prodrugs in combination with antibiotics to achieve enhanced bacterial killing [49].

In this study, we set out to evaluate the antimicrobial efficacy of diazeniumdiolate diethylamine NONOate (DEANONOate) against $E$. coli using both broth dilution and luminescent ATP assays to assess proof-of-concept for further evaluation of $\mathrm{NO}$ as a potential hand sanitization agent.

\section{Methods}

\section{Reagents}

DEA-NONOate (Enzo Biochem; Farmingdale NY), high performance liquid chromatography-grade water, and consumables were purchased from VWR Scientific (Radnor, PA). The BacTiter-Glo ${ }^{\mathrm{TM}}$ kits were provided as a generous donation from Promega Corporation (Madison, WI).

\section{Preparation of E. coli and Broth dilution and CFU assays}

We chose to examine the effects of DEA-NONOAte on $E$. coli as previous studies have shown that $E$. coli is susceptible to NO [50]. Briefly, E. coli ATCC $^{\bullet} 11229^{\mathrm{TM}}$ KWIKSTIK $^{\text {TM }}$ was inoculated on agar plates according to manufacturer's instructions using Mueller-Hinton (MH) medium (MilliporeSigma; Burlington, MA). An individual colony was selected and grown to midlog phase, in accordance with standard microbiological techniques, by growing the culture in $\mathrm{MH}$ medium overnight at $37{ }^{\circ} \mathrm{C}$ and $275 \mathrm{rpm}$ in a shaking incubator. The $E$. coli broth was then diluted to an absorbance of 0.01 (corresponding to $\sim 10$ million cell counts) for the broth dilution assay and transferred to 96 well plates. OD was determined using a spectrophotometer (BioTek Instruments, Inc.; Winooski, VT) and samples were analyzed at $630 \mathrm{~nm}$ as previously described for $\mathrm{MH}$ medium [51]. Each treatment, including the untreated control, was evaluated in sextuplicate $(n=6)$. For qualitative comparison of each treatment, CFUs were manually counted after $20 \mathrm{~h}$ of incubation on three plates in accordance with FDA guidelines [1].

DEA-NONOate stocks were prepared in water and diluted in $\mathrm{MH}$ broth to achieve final concentrations of 8 and $65 \mathrm{mM}$. DEA-NONOate $(65 \mathrm{mM})$ was selected as the high dose as it represented the theoretical maximum for the solubility of NO gas in water from a commercial gas cylinder at 500 psig [52]. DEA-NONOate $(8 \mathrm{mM})$ was selected as the low dose as scouting studies demonstrated bactericidal activity assessed after $3 \mathrm{~h}$ (data not shown). Ciprofloxacin was used as a 

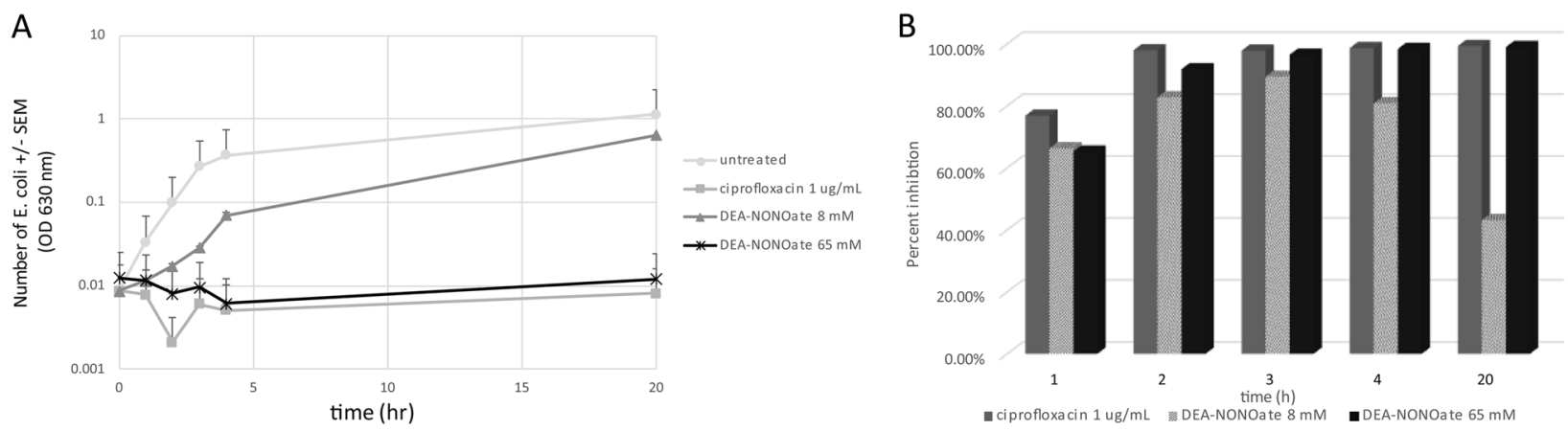

Fig. 1 E. coli were treated with DEA-NONOate and evaluated at various time points for growth inhibition. Each data point represents the average \pm SEM. a Inhibition of E. coli assessed by optical density (OD) growth assay, b percent inhibition as assessed by OD
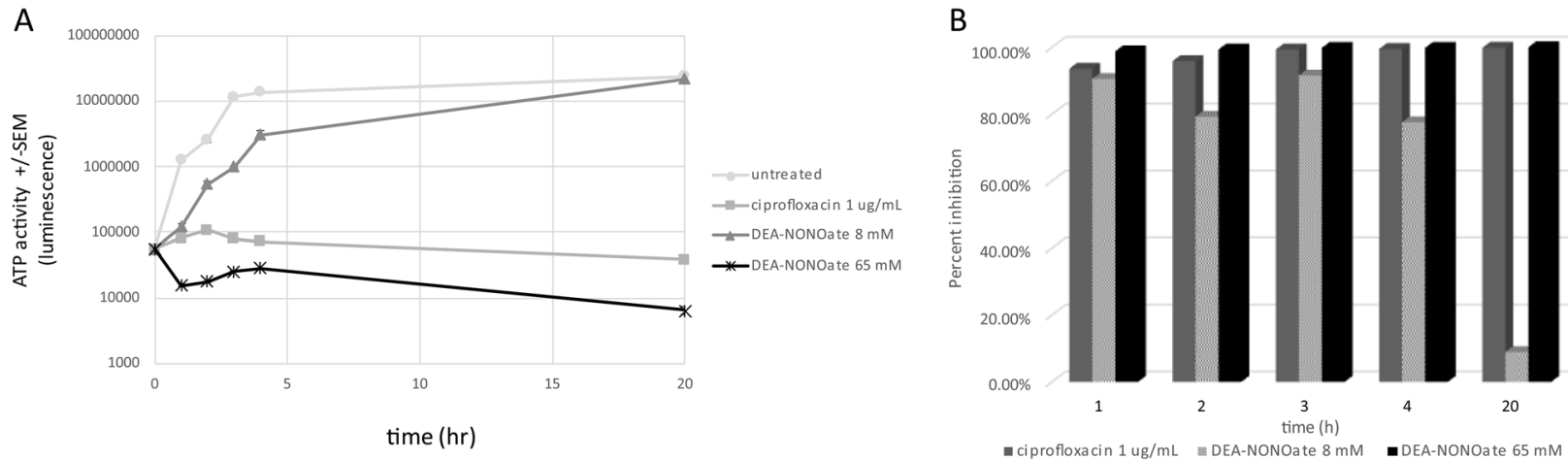

Fig. 2 E. coli were treated with DEA-NONOate and evaluated at various time points for growth inhibition. Each data point represents the average \pm SEM. a Inhibition of $E$. coli assessed by BacTiter-Glo ${ }^{\text {TM }}$ ATP activity, b percent inhibition as assessed by ATP activity

positive control at a concentration of $1 \mu \mathrm{g} \mathrm{ml} \mathrm{m}^{-1}$, which has shown to be effective against E. coli [53].

\section{BacTiter-Glo $^{\mathrm{Tm}}$ ATP assay}

A BacTiter-Glo ${ }^{\mathrm{TM}}$ Microbial Cell Viability assay was conducted according to manufacturer's instructions (Promega; Madison, WI). E. coli was diluted to a starting absorbance of 0.01. BacTiter-Glo ${ }^{\text {TM }}$ Reagent was added directly to the bacterial cells, supporting generation of a luminescent signal. Samples were transferred to 96 well white tissue culture plates and analyzed using a GloMax Navigator luminometer (Promega; Madison, WI). Each treatment, including the untreated control, was evaluated in sextuplicate $(n=6)$. Quantitation of cellular ATP, as indicated by luminescent signal, was proportional to the number of viable bacterial cells in each sample.

\section{Results}

At $20 \mathrm{~h}$, both ciprofloxacin $\left(1 \mu \mathrm{g} \mathrm{ml}^{-1}\right)$ and DEA-NONOate $(65 \mathrm{mM})$ inhibited bacterial growth, resulting in between 0 and 2 CFUs after manual counts of three agar plates. Untreated plates and DEA-NONOate $(8 \mathrm{mM})$-treated plates were fully confluent and could not be counted (data not shown).
Consistent with the plate counts, the broth dilution assay showed the greatest inhibition of $E$. coli growth by DEANONOate $(65 \mathrm{mM})$ at $20 \mathrm{~h}$, resulting in $99.9 \%$ reduction in E. coli (3 log reduction) (Fig. 1a, b). DEA-NONOate (65 $\mathrm{mM})$ outperformed ciprofloxacin $\left(1 \mu \mathrm{g} \mathrm{ml}^{-1}\right)$ at every time point in the BacTiter-Glo ${ }^{\mathrm{TM}}$ assay (Fig. 2a, b).

Growth inhibition assessing the optical density (OD) was comparable to the decrease in ATP activity illustrating the usefulness of the BacTiter-Glo ${ }^{\mathrm{TM}}$ assay as a viable addition to bacterial counting assays. Of interest, the antibacterial effects of DEA-NONOate at a concentration of $8 \mathrm{mM}$ were significant at all times points compared to untreated controls assessing the broth dilution assay similar to the ATP assay with the exception of the $20 \mathrm{~h}$ time point (BacTiter-Glo ${ }^{\mathrm{TM}}$ ) which was not significant.

\section{Discussion}

Currently, several hand sanitizers, including alcohol-based hand sanitizers [54], are not effective at killing bacteria and viruses as labeled, and are currently under review by the FDA. Antimicrobial resistance is among the top three threats to global health [55] and must be considered when designing a hand sanitization agent. 
The use of NO as a hand sanitizing agent is warranted based on the antimicrobial properties of NO and its proven use in various formulations [56]. Several studies have demonstrated antimicrobial activity of NO using diazeniumdiolates [47], the most widely available solid-dose form capable of generating NO. The diazeniumdiolate PROLI-NONOate [57], which very quickly releases NO, has demonstrated $99 \%$ growth inhibition (3 log reduction) of both Aggregatibacter actinomycetemcomitans and Porphyromonas gingivalis at a concentration of $25 \mathrm{mM}$ examined after a $2 \mathrm{~h}$ treatment period with no additional time points measured. Our study evaluated $8 \mathrm{mM}$ DEA-NONOate, which demonstrated $\sim 80 \%$ inhibition of $E$. coli at $2 \mathrm{~h}$; this effect was not sustained at $20 \mathrm{~h}$. DEA-NONOate has a slower release of $\mathrm{NO}\left(t / 2=2 \mathrm{~min}\right.$. at $\left.37^{\circ} \mathrm{C}\right)$ compared to PROLI-NONOate $\left(t^{1 / 2}=1.8 \mathrm{sec}\right.$. at $\left.37^{\circ} \mathrm{C}\right)$, which may account for differences in bactericidal effect. As well, treatments should ideally be examined at $20-24 \mathrm{~h}$ to appropriately determine log reduction [1].

Other NO-donors, including modified S-nitroso-penicillamine, have demonstrated inhibition of E. coli and S. epidermidis growth when used at concentrations in the low $\mathrm{mM}$ range [58]. A $2.5 \mathrm{mM}$ concentration of polyethyleniminebased NO donor had some efficacy against E. coli and Staphylococcus aureus bacterial suspensions [59] but failed to achieve $3 \log$ reduction. The NO-donor nitroso- $N$-acetylpenicillamine (SNAP) exhibited some activity against Coxsackievirus [60]; interestingly, this NO-donor induced nitrosylation of a critical cysteine residue in the active site of Coxsackievirus protease $3 \mathrm{C}$, and this reaction was proposed to be its mechanism of antibacterial action.

Both nitrate and nitrite have been shown to generate NO in vivo. Studies have examined the efficacy of nitrite as well as NO derived from a $0.002 \mathrm{mM}$ concentration of DETA-NONOate against E. coli and Shewanella oneidensis [50]; nitrite was more effective against $S$. oneidensis whereas NO was more effective against $E$. coli [50], which may be a result of nitrite reduction mechanisms. The antimicrobial action of NO derived from sodium nitrite against verotoxigenic E. coli O157:H7 was demonstrated at NO concentrations of $84 \mathrm{mM}$ [61] which compares more closely to the results of this study. Some studies have also shown that nitrite at $1 \mathrm{mM}$ can inhibit bacteria such as Helicobacter pylori [62]. Although our results demonstrate that much higher millimolar concentrations of NO are required to achieve $99.9 \%$ growth inhibition, differences in NO-donor antibacterial efficacy can most likely be attributed to the release characteristics specific to each NO donor.

Direct use of NO gas has been shown to be effective against E. coli, Pseudomonas aeruginosa, and S. aureus [63] as well as other bacterial pathogens [64]. A Phase I clinical trial of patients with cystic fibrosis demonstrated that $160 \mathrm{ppm}(5.3 \mathrm{mM}) \mathrm{NO}$ delivered for $30 \mathrm{~min}$ three times daily for 5 days, administered in 2 cycles, reduced CFU of several bacteria (including E.coli) and lessened lung infection [65]. Inhaled NO (6.6 mM) was also effective in treating patients with pneumonia [66]. A quantitative modeling study evaluated continuous in vitro NO generation and determined that a concentration of at least 0.002 $\mathrm{mM}$ was required for optimal antibacterial activity [67]. Another in vitro study [68] examined NO gas (5.3 mM), which demonstrated efficacy against $S$. aureus with 6 cycles of NO gas every $30 \mathrm{~min}$ via continuous exposure; however, the antibacterial effects may have been due to the production of nitrogen dioxide (derived from NO when reacted with oxygen) or the formation of peroxynitrite [69] (a product of NO) and superoxide [70], both of which have been shown to be antibacterial. Other studies have demonstrated an antibacterial response by peroxynitrite derived from NO [71].

Our study demonstrates the utility of NO against $E$. coli at concentrations of $8 \mathrm{mM}$ and $65 \mathrm{mM}$. A concentration of 65 mM DEA-NONOate after $20 \mathrm{~h}$ of exposure resulted in a 3-log reduction in bacterial growth in accordance with FDA guidelines. DEA-NONOate at $8 \mathrm{mM}$ was effective at reducing bacterial load at all time points compared to untreated controls which supports the use of low doses of DEA-NONOate, or other NO-donors, for use against lower bacterial loads such as those found on human hands. Hand sanitizers are tested on human hands at bacterial loads below 1 million CFUs, which is tenfold below the starting CFUs used in this study [72]. Normal bacteria skin flora is highest on the scalp at 1 million $\mathrm{CFUs} / \mathrm{cm}^{2}$ and has been shown to exceed 4 million CFUs on the hands of medical personnel [72, 73]. It will be interesting to assess $8 \mathrm{mM}$ DEA-NONOate in the clinical setting evaluating lower bacterial loads, which may support its use as an effective hand sanitizing agent with single or multiple uses in hand washing.

Differences in effective antibacterial concentration between this study and by other studies can be attributed to the nuances of each bacterial strain, bacterial load, growth conditions, exposure times, differences in NO donor release profiles, production of NO-derived oxidants such as peroxynitrite, measurement techniques or other confounding variables not readily identifiable.

Our study supports the use of the BacTiter-Glo ${ }^{\text {TM }}$ assay as a viable alternative to gold standard CFU plate counts. The BacTiter-Glo $^{\mathrm{TM}}$ assay correlated to the CFU counts as did OD of bacterial suspensions. The BacTiter-Glo ${ }^{\mathrm{TM}}$ assay thus represents a high-throughput method for evaluation of antimicrobial agent efficacy.

In conclusion, the application of $\mathrm{NO}$ as an antimicrobial agent is promising. Use of $\mathrm{NO}$, in combination with antibiotic agents, may be a viable option to address antibiotic resistance. FDA approval of NO as a hand sanitizing agent 
will require formal evaluation against a panel of bacteria and fungi, as well as clinical testing, but is much needed as effective hand sanitizing agents are in great demand.

Acknowledgements The GloMax Navigator was made possible through a generous gift from Promega Corporation. The authors wish to thank Aric Morgan (Promega) for his availability and support throughout the project. The authors wish to thank Dr Thomas Tallant (Walsh University) and Dr Darlene Walro (Walsh University) for performing the microbiology experiments.

\section{Compliance with ethical standards}

Conflict of interest The authors declare that they have no conflict of interest.

Publisher's note Springer Nature remains neutral with regard to jurisdictional claims in published maps and institutional affiliations.

\section{References}

1. United States Food and Drug Administration (FDA). Tentative final monograph for health-care antiseptic drug products; proposed rule. 21 CFR 236 Parts 333 and 369. vol. 59. Fed. Regist. Rockville, MD USA, US 1994, pp 31402-52.

2. Breed RS, Dotterrer WD. The number of colonies allowable on satisfactory agar plates. J Bacteriol. 1916;1:321-31.

3. Sutton S. Accuracy of plate counts. J Valid Technol. 2011;17: 42-6.

4. Kavanagh A, Ramu S, Gong Y, Cooper MA, Blaskovich MAT. Effects of microplate type and broth additives on microdilution MIC susceptibility assays. Antimicrobial Agents Chemother. 2019;63:1-17.

5. Clais S, Boulet G, Van Kerckhoven M, Lanckacker E, Delputte P, Maes L, et al. Comparison of viable plate count, turbidity measurement and real-time PCR for quantification of Porphyromonas gingivalis. Lett Appl Microbiol. 2015;60:79-84.

6. Sun W, Weingarten RA, Xu M, Southall N, Dai S, Shinn P, et al. Rapid antimicrobial susceptibility test for identification of new therapeutics and drug combinations against multidrug-resistant bacteria. Emerg Microbes Infect. 2016;5:e116.

7. Balouiri M, Sadiki M, Ibnsouda SK. Methods for in vitro evaluating antimicrobial activity: a review. J Pharm Anal. 2016;6: 71-9.

8. Kim SH, Park C, Chun HS, Lee DG, Choi JK, Lee HJ, et al. Pilot screening to determine antimicrobial synergies in a multidrugresistant bacterial strain library. Microb Drug Resist (Larchmt, NY). 2016;22:372-8.

9. Hunter DM, Lim DV. Rapid detection and identification of bacterial pathogens by using an ATP bioluminescence immunoassay. J Food Prot. 2010;73:739-46.

10. Rolain JM, Mallet MN, Fournier PE, Raoult D. Real-time PCR for universal antibiotic susceptibility testing. J Antimicrobial Chemother. 2004;54:538-41.

11. Hattori N, Nakajima MO, O'Hara K, Sawai T. Novel antibiotic susceptibility tests by the ATP-bioluminescence method using filamentous cell treatment. Antimicrobial Agents Chemother. 1998;42:1406-11.

12. Cai Y, Leck H, Lim TP, Teo J, Lee W, Hsu LY, et al. Using an adenosine triphosphate bioluminescent assay to determine effective antibiotic combinations against carbapenem-resistant gram negative bacteria within 24 h. PloS ONE. 2015;10:e0140446.
13. Ivancic V, Mastali M, Percy N, Gornbein J, Babbitt JT, Li Y, et al. Rapid antimicrobial susceptibility determination of uropathogens in clinical urine specimens by use of ATP bioluminescence. J Clin Microbiol. 2008;46:1213-9.

14. Heller AA, Spence DM. A rapid method for post-antibiotic bacterial susceptibility testing. PloS ONE. 2019;14:e0210534.

15. Lobritz MA, Belenky P, Porter CBM, Gutierrez A, Yang JH, Schwarz EG, et al. Antibiotic efficacy is linked to bacterial cellular respiration. Proc Natl Acad Sci. 2015;112:8173-80.

16. Poderoso JJ, Helfenberger K, Poderoso C. The effect of nitric oxide on mitochondrial respiration. Nitric oxide: Biol Chem. 2019;88:61-72.

17. Smith WD. A history of nitrous oxide and oxygen anaesthesia. I. Joseph Priestley to Humphry Davy. Br J Anaesth. 1965;37:790-8.

18. Farah C, Michel LYM, Balligand JL. Nitric oxide signalling in cardiovascular health and disease. Nat Rev Cardiol. 2018;15: 292-316.

19. Haloul M, Vinjamuri SJ, Naquiallah D, Mirza MI, Qureshi M, Hassan $\mathrm{C}$ et al. Hyperhomocysteinemia and low folate and vitamin B12 are associated with vascular dysfunction and impaired nitric oxide sensitivity in morbidly obese patients. Nutrients. 2020;12:2014.

20. Menzies-Gow A, Mansur AH, Brightling CE. Clinical utility of fractional exhaled nitric oxide in severe asthma management. Eur Respir J. 2020;55:1901633.

21. Griffiths MJ, Evans TW. Inhaled nitric oxide therapy in adults. N Engl J Med. 2005;353:2683-95.

22. Lambden S. Bench to bedside review: therapeutic modulation of nitric oxide in sepsis - an update. Intensive Care Med Exp. 2019;7:64.

23. Opatrilova R, Kubatka P, Caprnda M, Büsselberg D, Krasnik V, Vesely P, et al. Nitric oxide in the pathophysiology of retinopathy: evidences from preclinical and clinical researches. Acta Ophthalmol. 2018;96:222-31.

24. Kamm A, Przychodzen P, Kuban-Jankowska A, Jacewicz D, Dabrowska AM, Nussberger S, et al. Nitric oxide and its derivatives in the cancer battlefield. Nitric Oxide: Biol Chem. 2019;93:102-14.

25. Bonavida B. Sensitizing activities of nitric oxide donors for cancer resistance to anticancer therapeutic drugs. Biochemical Pharmacol. 2020;176:113913.

26. Boden WE, Padala SK, Cabral KP, Buschmann IR, Sidhu MS. Role of short-acting nitroglycerin in the management of ischemic heart disease. Drug Des Dev Ther. 2015;9:4793-805.

27. Moraca PP, Bitte EM, Hale DE, Wasmuth CE, Poutasse EF. Clinical evaluation of sodium nitroprusside as a hypotensive agent. Anesthesiology. 1962;23:193-9.

28. Chen L, Liu P, Gao H, Sun B, Chao D, Wang F, et al. Inhalation of nitric oxide in the treatment of severe acute respiratory syndrome: a rescue trial in Beijing. Clin Infect Dis. 2004;39:1531-5.

29. Dowell JC, Thomas NJ, Yehya N. Association of response to inhaled nitric oxide and duration of mechanical ventilation in pediatric acute respiratory distress syndrome. Pediatr Crit Care Med. 2017;18:1019-26.

30. Zamanian RT, Pollack CV Jr, Gentile MA, Rashid M, Fox JC, Mahaffey KW, et al. Outpatient inhaled nitric oxide in a patient with vasoreactive idiopathic pulmonary arterial hypertension and COVID-19 infection. Am J Respir Crit Care Med. 2020;202: 130-2.

31. Parikh R, Wilson C, Weinberg J, Gavin D, Murphy J, Reardon CC. Inhaled nitric oxide treatment in spontaneously breathing COVID-19 patients. Therapeutic Adv Respir Dis. 2020;14:1753466620933510.

32. Nathan C, Xie QW. Nitric oxide synthases: roles, tolls, and controls. Cell. 1994;78:915-8. 
33. Lundberg JO, Weitzberg E, Gladwin MT. The nitrate-nitrite-nitric oxide pathway in physiology and therapeutics. Nat Rev Drug Discov. 2008;7:156-67.

34. Kapil V, Khambata RS, Jones DA, Rathod K, Primus C, Massimo $\mathrm{G}$, et al. The noncanonical pathway for in vivo nitric oxide generation: the nitrate-nitrite-nitric oxide pathway. Pharmacol Rev. 2020;72:692-766.

35. Kelm M. Nitric oxide metabolism and breakdown. Biochimica et Biophysica Acta. 1999;1411:273-89.

36. Bogdan C. Nitric oxide synthase in innate and adaptive immunity: an update. Trends Immunol. 2015;36:161-78.

37. García-Ortiz A, Serrador JM. Nitric oxide signaling in T cellmediated immunity. Trends Mol Med. 2018;24:412-27.

38. Weiss G, Schaible UE. Macrophage defense mechanisms against intracellular bacteria. Immunological Rev. 2015;264:182-203.

39. Wink DA, Hines HB, Cheng RY, Switzer CH, Flores-Santana W, Vitek MP, et al. Nitric oxide and redox mechanisms in the immune response. J Leukoc Biol. 2011;89:873-91.

40. Keefer LK. Fifty years of diazeniumdiolate research. Lab Curiosit broad-Spectr Biomed Adv ACS Chem Biol. 2011;6:1147-55.

41. Keefer LK. Progress toward clinical application of the nitric oxide-releasing diazeniumdiolates. Annu Rev Pharmacol Toxicol. 2003;43:585-607.

42. Zhou X, Zhang J, Feng G, Shen J, Kong D, Zhao Q. Nitric oxidereleasing biomaterials for biomedical applications. Curr Med Chem. 2016;23:2579-601.

43. Rong F, Tang Y, Wang T, Feng T, Song J, Li P, et al. Nitric oxide-releasing polymeric materials for antimicrobial applications: a review. Antioxidants. 2019;8:556.

44. Nguyen TK, Selvanayagam R, Ho KKK, Chen R, Kutty SK, Rice SA, et al. Co-delivery of nitric oxide and antibiotic using polymeric nanoparticles. Chem Sci. 2016;7:1016-27.

45. Powell KL, Baylis SA. The antiviral effects of nitric oxide. Trends Microbiol. 1995;3:81-2.

46. Abdul-Cader MS, Amarasinghe A, Abdul-Careem MF. Activation of toll-like receptor signaling pathways leading to nitric oxide-mediated antiviral responses. Arch Virol. 2016;161: 2075-86.

47. Li B, Ming Y, Liu Y, Xing H, Fu R, Li Z, et al. Recent developments in pharmacological effect, mechanism and application prospect of diazeniumdiolates. Front Pharmacol. 2020;11:923.

48. Schairer DO, Chouake JS, Nosanchuk JD, Friedman AJ. The potential of nitric oxide releasing therapies as antimicrobial agents. Virulence. 2012;3:271-9.

49. Jubeh B, Breijyeh Z, Karaman R. Antibacterial prodrugs to overcome bacterial resistance. Molecules. 2020;25:1543.

50. Meng Q, Yin J, Jin M, Gao H. Distinct nitrite and nitric oxide physiologies in Escherichia coli and Shewanella oneidensis. Appl Environ Microbiol. 2018;84:e00559-18.

51. Yang B, Lei Z, Zhao Y, Ahmed S, Wang C, Zhang S, et al. Combination susceptibility testing of common antimicrobials in vitro and the effects of sub-MIC of antimicrobials on Staphylococcus aureus biofilm formation. Front Microbiol. 2017;8:2125.

52. Shaw AW, Vosper AJ. Solubility of nitric oxide in aqueous and nonaqueous solvents. J Chem Soc, Faraday Trans 1: Phys Chem Condens Phases. 1977;73:1239-44.

53. Fantin B, Duval X, Massias L, Alavoine L, Chau F, Retout S, et al. Ciprofloxacin dosage and emergence of resistance in human commensal bacteria. J Infect Dis. 2009;200:390-8.

54. Ribeiro MM, Neumann VA, Padoveze MC, Graziano KU. Efficacy and effectiveness of alcohol in the disinfection of semicritical materials: a systematic review. Rev Lat-Am de Enferm. 2015;23:741-52.
55. Santajit $\mathrm{S}$, Indrawattana N. Mechanisms of antimicrobial resistance in ESKAPE pathogens. BioMed Res Int. 2016;2016:2475067.

56. Jones ML, Ganopolsky JG, Labbé A, Wahl C, Prakash S. Antimicrobial properties of nitric oxide and its application in antimicrobial formulations and medical devices. Appl Microbiol Biotechnol. 2010;88:401-7.

57. Backlund CJ, Sergesketter AR, Offenbacher S, Schoenfisch MH. Antibacterial efficacy of exogenous nitric oxide on periodontal pathogens. J Dent Res. 2014;93:1089-94.

58. Reger NA, Meng WS, Gawalt ES. Antimicrobial activity of nitric oxide-releasing Ti-6Al-4V metal oxide. J Funct Biomater. 2017; $8: 20$.

59. Ji Y, Li G, Zhang W, Ma D, Xue W. Cross-linked branched polyethylenimine used as a nitric oxide donor for prolonged nitric oxide release. Materials science \& engineering C. Mater Biol Appl. 2017;81:492-9.

60. Saura M, Zaragoza C, McMillan A, Quick RA, Hohenadl C, Lowenstein JM, et al. An antiviral mechanism of nitric oxide: inhibition of a viral protease. Immunity. 1999;10:21-8.

61. Morita H, Yoshikawa H, Suzuki T, Hisamatsu S, Kato Y, Sakata $\mathrm{R}$, et al. Anti-microbial action against verotoxigenic Escherichia coli $\mathrm{O} 157: \mathrm{H} 7$ of nitric oxide derived from sodium nitrite. Biosci, Biotechnol, Biochem. 2004;68:1027-34.

62. Dykhuizen RS, Fraser A, McKenzie H, Golden M, Leifert C, Benjamin N. Helicobacter pylori is killed by nitrite under acidic conditions. Gut. 1998;42:334-7.

63. Ghaffari A, Neil DH, Ardakani A, Road J, Ghahary A, Miller CC. A direct nitric oxide gas delivery system for bacterial and mammalian cell cultures. Nitric oxide: Biol Chem. 2005;12:129-40.

64. Ghaffari A, Jalili R, Ghaffari M, Miller C, Ghahary A. Efficacy of gaseous nitric oxide in the treatment of skin and soft tissue infections. Wound repair and regeneration: official publication of the Wound Healing. Soc [] Eur Tissue Repair Soc. 2007;15:368-77.

65. Deppisch C, Herrmann G, Graepler-Mainka U, Wirtz H, Heyder $\mathrm{S}$, Engel $\mathrm{C}$, et al. Gaseous nitric oxide to treat antibiotic resistant bacterial and fungal lung infections in patients with cystic fibrosis: a phase I clinical study. Infection. 2016;44:513-20.

66. McMullin BB, Chittock DR, Roscoe DL, Garcha H, Wang L, Miller CC. The antimicrobial effect of nitric oxide on the bacteria that cause nosocomial pneumonia in mechanically ventilated patients in the intensive care unit. Respir Care. 2005;50:1451-6.

67. Sivaloganathan DM, Brynildsen MP. Quantitative modeling extends the antibacterial activity of nitric oxide. Front Physiol. 2020;11:330

68. Miller C, McMullin B, Ghaffari A, Stenzler A, Pick N, Roscoe D, et al. Gaseous nitric oxide bactericidal activity retained during intermittent high-dose short duration exposure. Nitric oxide: Biol Chem. 2009;20:16-23.

69. Zhu L, Gunn C, Beckman JS. Bactericidal activity of peroxynitrite. Arch Biochem Biophys. 1992;298:452-7.

70. Radi R. Oxygen radicals, nitric oxide, and peroxynitrite: Redox pathways in molecular medicine. Proc Natl Acad Sci USA. 2018;115:5839-48.

71. Hoang Thi TT, Lee Y, Le Thi P, Park KD. Nitric oxide-releasing injectable hydrogels with high antibacterial activity through in situ formation of peroxynitrite. Acta Biomaterialia. 2018;67:66-78.

72. Boyce JM, Pittet D. Guideline for Hand Hygiene in Health-Care Settings. Recommendations of the Healthcare Infection Control Practices Advisory Committee and the HIPAC/SHEA/APIC/ IDSA Hand Hygiene Task Force. Am J Infect Control. 2002;30: S1-46.

73. Selwyn S. Microbiology and ecology of human skin. Practitioner. 1980;224:1059-62. 